\title{
Populismo y deporte en América Latina: nuevas y viejas formas de discutir la patria
}

\author{
Pablo Alabarces*
}

\begin{abstract}
* Licenciado en Letras por la Universidad de Buenos Aires (UBA), magister en Sociología de la Cultura por la Universidad Nacional de San Martin (UNSAM) y doctor en Sociología por la Universidad de Brighton, Inglaterra. Es profesor titular de Cultura Popular en la Facultad de Ciencias Sociales de la Universidad de Buenos Aires, en la que dirigió su Doctorado entre 2004 y 2010, e Investigador Principal del CONICET. Es considerado uno de los fundadores de la sociología del deporte latinoamericana. Ha publicado catorce libros: entre ellos, Fútbol y Patria (2002), Peronistas, populistas y plebeyos (2010) y el último, Historia Minima del Fútbol en América Latina, editado en 2018 por El Colegio de México. Su libro Héroes, machos y patriotas, de 2014, ganó el Segundo Premio Nacional de Ensayo Sociológico en la Argentina (2019). Correo electrónico: palabarces@gmail.com
\end{abstract}

Fecha de recepción: 07/04/20. Fecha de aceptación: 16/05/20. 


\section{Populismo y deporte en América Latina: nuevas y viejas formas de discutir la patria}

\section{Resumen}

Desde que en 1904 el presidente argentino Julio Roca asistiera en Buenos Aires al juego entre el equipo local Alumni y el inglés Southampton, las relaciones entre deporte y política en América Latina fueron siempre muy estrechas. Especialmente en torno del fútbol: a medida que el deporte fue transformándose en práctica y consumo de las clases populares - lo que se conoce como el proceso de popularización del deporte, entre las décadas de 1910 y 1930 en todo el continente-, las élites políticas intentaron utilizarlo como un espacio de obtención de visibilidad y popularidad. Pero a partir de la década de 1930, apareció otra posibilidad política: el deporte se convirtió en una herramienta para construir narrativas nacionales populares, a través de las cuales las naciones se autorrepresentaban como encarnaciones de un pueblo y en las que las estrellas deportivas eran los nuevos héroes. Estos procesos acompañaron el surgimiento exitoso de las experiencias populistas latinoamericanas - especialmente, el varguismo brasileño y el peronismo argentino-, pero también instalaron un modo de narrar el deporte que continuó hasta nuestros días. Este trabajo presenta un análisis de ese proceso y un balance de la situación contemporánea, especialmente atento a las fluctuaciones entre populismos de izquierda — la marea rosada latinoamericana entre 200 y 2015 — y de derecha — las restauraciones conservadoras de los últimos ańos.

\section{Populism and Sports in Latin America: old and new ways of narrating the nation}

\section{Abstract}

Ever since 1904, when Argentine President Julio Argentino Roca attended a match between local team Alumni and English club Southampton in Buenos Aires, the relationship between sports and politics in Latin America has always been close. This is especially true for football: as the sport became a practice and product consumed by the popular classes - known as the process of popularisation, from 1910 to the 1930s throughout the whole continent-, the political elites tried to utilise it as a space to obtain visibility and popularity. But as of the '30s, another political possibility emerged: sport as a tool in the construction of popular national narratives through which nations represent themselves as the incarnation of its people and in which sports stars are the new heroes. These processes not only accompanied the successful emergence of Latin American populist experiences - Brazilian Varguism and Argentine Peronism, in particular-, but they also installed a way of narrating the sport that continues to be used today. This chapter presents an analysis of the aforementioned process and a balance of the contemporary situation, paying special attention to the fluctuations between the populisms of the Left — the Pink Tide of Latin America between 2000 and 2015- and the Right - the conservative restorations of recent years. 


\section{DE LA PROTECCIÓN CONSERVADORA A LA PRÁCTICA POPULISTA}

En 1912, el presidente argentino Sáenz Peña encargó una misión diplomática en Río de Janeiro al expresidente Julio Roca (1880-1886 y 1898-1904), quien aprovechó una visita de un combinado argentino a Brasil para acompañarlos en dos juegos amistosos contra combinados cariocas y paulistas — la selección brasileña no se había aún inventado. Roca ya había llevado al equipo argentino en 1908 en otra visita diplomática: en el partido entre la selección y un combinado carioca-paulista, el equipo rioplatense ganó por 3 a 2. Los partidos de 1912 fueron en ambas ciudades brasileñas, lo que permitió que en São Paulo jugaran los paulistas (perdieron 6 a 2) y en Río, salomónicamente, los cariocas (perdieron 4 a 0 ).

Evidentemente, al expresidente argentino le gustaba el fútbol, ya que en 1904 había sido el primer presidente latinoamericano en presenciar un juego internacional - la derrota del argentino Alumni frente al inglés Southampton por 3 a 0, en 1904, el primer partido internacional de la historia futbolística argentina y, posiblemente, en todo el continente. El día del segundo partido en Río nació otra leyenda: al finalizar el primer tiempo, con goles de Ernesto Brown, Alberto Ohaco y dos de Harry Hayes, Argentina ya ganaba 4 a 0 . Roca fue al vestuario argentino y pidió a los jugadores «dejarse ganar por la patria». Como la estadística afirma que el partido terminó con los mismos cuatro goles de diferencia, cabe pensar que la influencia política de Roca - militar y político que dominó cuarenta años de la escena argentina, desde 1879 hasta su muerte en 1914- era inversamente proporcional a su influencia futbolera. Por otro lado, una leyenda paralela relata que el capitán del equipo argentino, el mítico Juan Brown, jugador del Alumni, le respondió: «General, la política es la política y el fútbol es el fútbol». Fuera de la leyenda, los partidos existieron realmente, y hay fotos de Roca en el estadio Das Laranjeiras junto al presidente brasileño, el mariscal Hermes Rodrigues da Fonseca, y el ministro Manuel Ferraz de Campos Sales, la alta política de ambos países.

Durante los primeros años del siglo XX fue constante la presencia de los jefes de Estado latinoamericanos en eventos deportivos: inauguraban estadios, entregaban trofeos, presenciaban juegos importantes, incluían al fútbol en las currículas escolares, intervenían para solucionar crisis institucionales en las asociaciones futbolísticas —el caso simultáneo de Argentina y Uruguay en 1926. Desde apenas iniciado el siglo XX, pero muy especialmente cuando los procesos de popularización estaban avanzados - y, por ende, el fútbol se transformaba en un hecho de masas - , los políticos de todas las ideologías — en realidad, eran todos conservadores - se enfrascaron en los avatares futbolísticos. Imaginaban, sospechaban o comprendían que los deseos populares encontraban en el fútbol un campo fértil para crecer, y decidían aplicar el viejo lema panem et circens (pan y circo), en la idea 
(falaz) de que el entretenimiento futbolístico los preservaba de otros riesgos, tales como las huelgas y las rebeliones.

Por supuesto, este es un campo de opiniones contrapuestas, que nunca ha saldado la discusión sobre la eficacia. Una mirada rápida a la historia latinoamericana nos diría que las huelgas y las rebeliones se expandieron por todo el continente incluso, las revoluciones-, sin que la utilización política del fútbol haya hecho mucho para evitarlas o prevenirlas: o al menos, demorarlas. En general, la historia política no ha prestado atención a la mayor o menor presencia del fútbol en una sociedad para explicar causas o consecuencias de fenómenos políticos, económicos y sociales; nadie se ha animado a afirmar nunca que alguna insurrección o protesta popular dejó de producirse porque los sujetos estaban demasiado ocupados viendo los juegos de Pelé.

Sin embargo, esa discusión sobre la eficacia política de la instrumentación desde el poder de "cortinas de humo» futboleras coincide, sí, en una cosa: los gobernantes creyeron y creen a pie juntillas en que esa eficacia es indudable, y que cuanto más fútbol se brinde a las masas, menos estarán dispuestas a la revuelta o la protesta, y que cuantos más éxitos deportivos acredite un político en su período de gobierno, más posibilidades tendrá de pasar a la historia o, al menos, a la memoria popular. Es decir: esa relación no existe — jamás ha sido verificada-, pero los grupos dominantes creen en ella como verdad revelada.

Es difícil encontrar casos en los que la atención política sobre los fenómenos deportivos proceda de vocaciones populares y democráticas: de que alguna política deportiva se plantee la necesidad de expandir la práctica y el consumo de deporte simplemente como derecho popular. Posiblemente, las excepciones hayan sido la política deportiva del primer peronismo argentino; o más drásticamente, el caso cubano luego de la Revolución de 1959, o incluso su imitación por la Nicaragua sandinista de 1979; pero, en ambos casos, el fútbol no estaba involucrado. Por otro lado, el fútbol se volvió muy tempranamente un hecho de masas y, en consecuencia, un espectáculo, una mercancía, de la que los estados nacionales tenían pocas posibilidades de adueñarse y menos intenciones aún de distribuirla democráticamente. Es posible que la excepción más marcada sea la muy reciente nacionalización de las transmisiones televisivas futbolísticas en la Argentina, entre 2009 y 2016; pero incluso esta misma, el más notorio avance sobre la propiedad "privada" de los monopolios televisivos sobre el relato futbolístico en el continente, tuvo mucho más que ver con el objetivo del gobierno peronista de atacar al Grupo Multimedios Clarín - el propietario y usufructuario de los derechos televisivos- que con la alegada «democratización» que pregonaron. De todas maneras, volveré sobre este caso.

Sin embargo, como dijimos, la presencia de los gobernantes y de las políticas estatales acompaña hasta hoy todo el proceso que estamos narrando. Si la mera con- 
currencia al estadio ya es una señal —el presidente argentino Julio Roca atendiendo en 1904 el juego entre Alumni y Southampton compartía, en última instancia, un espectáculo de su propia clase social para sí misma-, eso se vuelve sistema luego de 1930 con la dictadura — y posterior gobierno democrático- de Getulio Vargas en Brasil, según afirma el historiador alemán Stefan Rinke (Rinke 2007). Hasta ese momento, existía la intervención más o menos activa a nivel escolar o institucional, o meramente honorífica - la concesión de un premio, por ejemplo. Desde la década de 1930, en todo el continente aparece la intervención activa en la construcción de estadios, en algunos casos propiedad de los estados locales -el Nacional de Lima, inaugurado por el dictador Leguía ya en 1923 y reinaugurado por el dictador Odría en 1952; el Nacional de Santiago de Chile, inaugurado por Arturo Alessandri en 1938 y reinaugurado (para la Copa del Mundo) por su hijo, también presidente, Jorge Alessandri en 1962. Pero también ocurre con los estadios propiedad de clubes: tanto el Monumental, de River Plate, como la Bombonera, de Boca Juniors, se construyen en la misma década — 1938 el de River, 1940 el de Boca- y en ambos casos gracias a la concesión de créditos baratos por el estado nacional — presidido por el general Justo, surgido del fraude conservador de esos ańos. Como nota "pintoresca», el estadio de River fue a su vez remodelado y reinaugurado en 1978 por la dictadura del general Videla para que fuera sede central de la Copa de ese año.

El varguismo, como se conoce al período de la historia política brasileña que va de 1930 hasta el suicidio de Vargas en 1954, fue el primer populismo exitoso en América Latina; la enorme atención que le prestó al deporte solo pudo ser emulada por el segundo gran populismo, que fue el peronismo argentino entre 1945 y 1955 , con regresos al poder entre 1973-1976, 1989-1999 y 2002-2015. Esa atención la podemos ver en la construcción de estadios —especialmente, el Pacaembú, de São Paulo, inaugurado en 1940; el Maracaná no fue construido por Vargas sino por su sucesor, Gaspar Dutra-, o en la creación de un Conselho Nacional de Desportos (CND), en 1941, la primer institución política dedicada a desarrollar, justamente, políticas deportivas con alcance nacional — recordemos que Brasil era, hasta esos años, un país poco integrado por su extensión geográfica y sus disparidades sociales, económicas, políticas y culturales. Y también en la atención brindada por la flamante Rádio Nacional, creada por Vargas en 1936, basada en Río de Janeiro pero con alcance nacional, y que contribuyó a la difusión del fútbol en todo el territorio.

Más ampliamente, lo que el varguismo desplegó fue una operación mediante la cual capturó las grandes formaciones culturales populares —el samba, el fútbol, el carnaval, la capoeira - para volverlas símbolos nacionales propuestos por el estado central, según analizó el antropólogo brasileño Renato Ortiz (Ortiz 1991). Los éxitos futbolísticos desde 1938 en adelante, a nivel sudamericano y luego mundial, 
contribuyeron a esta operación: permitían escamotear las desigualdades raciales con el mito de la democracia racial futbolística; o permitían combatir el «complexo de vira-lata» (una traducción aproximada sería "complejo de perro callejero»), una expresión acuñada por el periodista y dramaturgo Nelson Rodrigues para denominar un presunto «complejo de inferioridad» brasileño, que los éxitos entre 1958 y 1970 desmentían futbolísticamente. Y fue el periodista deportivo Mario Filho, gran impulsor de la Copa de 1950 y de la construcción del Maracaná —y devoto varguista- el inventor también del primer desfile de escuelas de samba (escolas de samba) en el Carnaval carioca: fue un invento de su jornal Mundo Esportivo, en 1932, para cubrir los meses de menor información deportiva por la falta de torneos. Al poco tiempo, como sabemos, los carnavales se convirtieron en uno de los mayores atractivos turísticos de la ciudad y otro de los símbolos nacionales.

\section{EL PRIMER POPULISMO ARGENTINO}

Como analiza Alabarces (2002) en Fútbol y Patria, la relación entre el Estado argentino y el fútbol fue muy cambiante, pero explotó durante el peronismo: las historias deportivas, en las que héroes plebeyos alcanzaban la gloria internacional representando al "pueblo», eran minuciosamente coherentes con las narrativas propuestas por el estado peronista entre 1945 y 1955, lo que puede verse en los relatos periodísticos -el Estado editaba una publicación semanal de masas específicamente deportiva, Mundo Deportivo, que proponía la «interpretación peronista» de los sucesos deportivos - y también los cinematográficos — que no eran estatales, pero estaban organizados por un "clima de época». Pero el peronismo también actuó en planos más concretos y pedestres, no solo en los narrativos. En un libro reciente sobre el período, el historiador israelí Ranaan Rein señala que el peronismo se presentó simultáneamente como muchas cosas: propaganda estatal, por supuesto, e intentos de control social amparados en la presunta "reconciliación de clases» que el populismo intentaba - e intenta—, pero a la vez, el peronismo propuso, como dijimos, la producción de narraciones democráticas donde los héroes populares deportivos podían representar lo patriótico, y también, el establecimiento de políticas deportivas de masas (Rein, 2015). En los casos que analizan Rein y sus colaboradores, se ve con claridad que la intervención del gobierno era compleja. Por ejemplo, en la huelga de jugadores de fútbol de 1948 se puede ver la negociación entre distintos actores: funcionarios, figuras claves del gobierno - la misma Eva Perón-, dirigentes deportivos, sindicalistas, con posturas que incluso contradecían las directivas oficiales y que no fueron autoritariamente sofocadas - la resolución del conflicto distó de responder a las expectativas oficiales. 
A su vez, la investigación de Rein parte de la base de que los clubes deportivos, asociaciones civiles en la Argentina, fueron mediadores claves en la organización del fenómeno: el análisis de distintos casos muestra las distintas relaciones que los clubes populares entablaban con el estado nacional o provincial, negociando con minucia la pleitesía — moderada o desbordada — y los beneficios, generalmente en forma de créditos para instalaciones deportivas o simplemente para salir de situaciones difíciles. Si bien cierta mitología hace foco en el caso del Racing Club, favorecido por créditos oficiales para la construcción de su nuevo estadio —al que bautizaron, por supuesto, Presidente Perón—, la investigación histórica revela dos cosas: por un lado, que el actor principal era el ministro Ramón Cereijo, hincha fanático de Racing, y no directamente Perón — del que nunca se supo con claridad si era hincha de Racing, de Boca o si directamente le importaba muy poco el fútbol. Por el otro, el hecho de que un decreto de 1947 que habilitaba la concesión de préstamos a las instituciones deportivas reproducía uno similar dictado, diez ańos antes, por la presidencia conservadora del general Justo.

En 1951, Argentina e Inglaterra jugaron el primer partido de su historia en Wembley: venció el equipo inglés por 2 a 1, en lo que los argentinos juzgaron una derrota digna donde el arquero Miguel Rugilo fue el héroe infaltable (fue apodado «el León de Wembley»). La revancha se jugó dos años después en Buenos Aires, y Argentina derrotó por primera vez a "la pérfida Albión" por 3 a 1: el héroe fue en este caso el jugador Ernesto Grillo, que convirtió un gol tildado como «rioplatense» por la eufórica prensa deportiva de la época - la calificación aludía a que el gol había combinado sorpresa, gambeta y calidad, rasgos típicos del «estilo criollo». El escritor argentino Osvaldo Bayer, en el guion que escribió para el film documental Fútbol argentino, afirma haber encontrado un diario de la época en el que se dijo: «Primero nacionalizamos los ferrocarriles [Perón lo había hecho en 1949], hoy nacionalizamos el fútbol» (Bayer, 1990).

El partido se jugó el 14 de mayo de 1953: en su recuerdo se celebra el Día del Futbolista Argentino, en un nuevo pliegue del invariable narcisismo local.

\section{Tiempos MilitARES}

Pocos años después, ya en la década de 1960, casi todo el subcontinente vivía bajo regímenes militares, lo que fue perfeccionado en la década siguiente; en 1978, solo México, Costa Rica y Venezuela disfrutaban de regímenes democráticos, mientras que Colombia vivía en la guerra civil. Los modos en que el fútbol experimentaba las consecuencias de los totalitarismos latinoamericanos fueron bastante distintos y merecen que los narremos. 
Posiblemente, el caso más interesante sea el peruano: estos años coinciden con su ciclo dorado futbolístico, que se inició cuando en 1969 eliminaron a Argentina de la Copa del Mundo de México 1970, venciéndola en Lima e igualando en Buenos Aires. Perú tuvo un gran desempeño en la Copa, aunque fue eliminado en cuartos de final por el finalmente campeón Brasil. En 1975, la misma generación de jugadores obtuvo la Copa América por segunda vez (había vencido en el Sudamericano de Lima, en 1939). En 1978, volvieron a clasificar a la Copa de Argentina, en la que pasaron a la segunda fase, y fueron vencidos por Polonia, Brasil y Argentina —este último juego merecerá un relato especial, más adelante. En 1982 también clasificaron a la Copa española, pero fueron eliminados en primera ronda. Allí concluyó el ciclo dorado: Perú no volvió a clasificar a una Copa, hasta su clasificación para el mundial organizado en Rusia en 2018.

En Perú, la dictadura contemporánea fue la de uno de los pocos gobiernos militares reformistas del continente, la del general Velasco Alvarado, entre 1968 y 1975 (luego continuada por el general Morales Bermúdez hasta 1980, que giró drásticamente a la derecha y se asoció con el resto de las dictaduras fascistas del continente). La dictadura de Velasco intentó un modelo nacionalista que incluía la reivindicación de los eternos invisibilizados en Perú: las poblaciones originarias. Como ya señalamos, los afrodescendientes habían sido parte de un primer proceso de democratización del fútbol en la década de 1930; en la de 1960, lo fueron los descendientes de los antiguos incas, los llamados «cholos». La selección peruana más exitosa de su historia, la que jugó entre 1969 y 1980, era un equipo de negros y cholos; algunos de ellos estuvieron entre los mejores jugadores de la historia latinoamericana, como el ya citado zaguero Julio Meléndez, ídolo del Boca argentino; y junto a él, los cholos Héctor Chumpitaz y Hugo Sotil, y el negro Teófilo Cubillas, un jugador inolvidable (ver especialmente Panfichi, 2008).

Las cosas no fueron mejores en Chile, que obtuvo el tercer puesto en su propia Copa, en 1962. En 1966, Chile fue eliminada en primera ronda, con apenas un empate ante Corea del Norte. En 1970 no pudo clasificar, eliminada por Uruguay. Lo peor aún no había ocurrido.

En 1973, el general fascista Augusto Pinochet derrocó sangrientamente al gobierno democrático del socialista Salvador Allende, en el mismo momento en que la selección jugaba la eliminatoria mundialista. Chile eliminó a Perú luego de tres juegos, pero debió jugar un repechaje contra la entonces Unión de Repúblicas Socialistas Soviéticas (URSS), luego del golpe de septiembre. Chile igualó en Moscú el 26 de ese mes, y la revancha debía jugarse en Santiago el 21 de noviembre. Pero el Estadio Nacional, el espacio designado para el juego, había sido transformado por la dictadura en campo de concentración y exterminio de detenidos políticos; la URSS, entonces, protestó ante la FIFA y solicitó jugar en una ciudad 
neutral. Después de muchos debates, la FIFA aceptó enviar una inspección, que no encontró nada que objetar y obligó a la URSS a jugar el partido. Los soviéticos se negaron; Chile salió a la cancha el 21 de noviembre y se le reconoció ganado el partido. Jugó la Copa obteniendo apenas un gol y dos empates, quedando eliminada en primera ronda. Luego de ser eliminada en la clasificación de 1978, llegó a Espańa 1982, donde fue derrotada en los tres juegos de la primera ronda.

El gobierno pinochetista tuvo una activa injerencia en el mundo futbolístico, interviniendo la Asociación y forzando dirigencias adictas, que llevaron al fútbol chileno a una aguda crisis económica —entre otras cosas, inventaron un torneo de veintiséis equipos en 1984, que fue un notorio fracaso de asistencia a los estadios. Pero el peor hecho ocurrió al final de la dictadura. En la clasificación de 1989 para la Copa de 1990, en un partido decisivo contra Brasil en el Maracaná, el arquero chileno Roberto Rojas simuló ser herido por una bengala y el equipo abandonó el campo argumentando falta de garantías. La investigación de FIFA reveló que Rojas se había herido a sí mismo con una hoja de afeitar escondida; la selección chilena fue eliminada y sancionada, por lo que no pudo jugar tampoco la eliminatoria siguiente (ver especialmente Elsey, 2011).

La dictadura paraguaya del general Alfredo Stroesnner fue la más prolongada del continente: comenzó en 1954 y duró hasta 1989. Pero no afectó decisivamente el fútbol "guaraní»: sencillamente, el fútbol en Paraguay experimentó en toda su historia problemas derivados de la informalidad, la dependencia de las crisis políticas, las guerras civiles o las guerras internacionales (contra Bolivia, entre 1932 y 1935), la corrupción de sus dirigencias. Paraguay ganó el Campeonato Sudamericano de 1953, del que fue sede, pero jugando el torneo en Lima —en 1924 había ocurrido lo mismo, pero se jugó en Montevideo; en ambas ocasiones, la Liga Paraguaya debió organizar el torneo en otro país por falta de infraestructura adecuada. Solo en 1999 organizaría una Copa América en territorio paraguayo. Jugó las copas del mundo de 1930, 1950 y 1958, con malos resultados; solo pasó a octavos de final en México, en 1986, lo que repitió en Francia, en 1998, donde fue derrotada por el local (y a la postre campeón). Esa historia política inestable, más sus desempeños irregulares y su informalidad institucional —el profesionalismo nunca fue instaurado legalmente - condujeron a que los grandes jugadores paraguayos alcanzaron el estrellato jugando en el exterior: Arsenio Erico, quien posiblemente haya sido en la década de 1930 el mejor jugador del mundo, brilló en Independiente de Argentina y es aún el más grande goleador de la historia de ese país; Delfín Benítez Cáceres fue figura del Boca Juniors en la misma década; Roque Santa Cruz lo fue en Alemania en la primera década de este siglo; Julio César Romero fue ídolo del Cosmos norteamericano y del Fluminense brasileño en los ochenta; José Luis Chilavert fue la estrella del Vélez Sarsfield argentino multicampeón en los noventa y mejor arquero del mundo en la Copa de Francia, en 1998. 
Pero además de esta historia futbolera, Paraguay legó a América Latina una historia dirigencial como herencia de la dictadura stroessnerista. En 1986 llegó a la presidencia de la Conmebol el paraguayo Nicolás Leoz — que ya era vicepresidente desde 1980, bajo la conducción del peruano Teófilo Salinas-. Lo hizo en alianza con el poder continental representado por el mandamás argentino, Julio Grondona —presidente de AFA entre 1979 y 2014—, y el brasileño, Ricardo Teixeira — presidente de la CBF entre 1987 y 2012, y yerno de João Havelange, presidente a su vez de la FIFA entre 1974 y 1998. Leoz consiguió mudar la sede de la Conmebol a Luque, ciudad vecina de Asunción, en 1988, donde el gobierno paraguayo le concedió al edificio un insólito estatuto extraterritorial. En 2012, Leoz fue elegido presidente vitalicio de la Conmebol. De todos ellos, Grondona se salvó de la cárcel porque murió antes del escándalo de 2015; Leoz fue obligado a renunciar a la Confederación y está procesado con prisión domiciliaria, al igual que Teixeira, renunciante a la CBF en 2012. Havelange fue procesado, pero escapó a la cárcel con el mismo recurso que Grondona: se murió en 2016. Todos ellos fueron las grandes responsables de la extraordinaria corrupción del fútbol sudamericano, especialmente vinculada a la venta ilegal de derechos televisivos o de votos en la elección de las sedes de las Copas del Mundo -en alianza con Sepp Blatter, sucesor de Havelange en la FIFA desde 1998 hasta su expulsión en 2015.

Argentina fue elegida sede de la Copa del Mundo de 1978 doce años antes, en 1966; en ese momento había un presidente democrático; cuando los dirigentes regresaron a la Argentina, reinaba el dictador Onganía. Los primeros pasos serios de la organización se dieron durante el gobierno democrático de 1973; la organización definitiva la tuvo la peor dictadura de la historia argentina, que se instaló en 1976 y duró hasta 1983.

Argentina ganó su propio campeonato - fue el último país sede en hacerlo hasta Francia 1998 - y desde entonces no ha vuelto a repetirse. Tanto la organización como el desarrollo del torneo se hicieron en un clima ominoso y represivo, que incluyó la prohibición explícita de criticar en los medios deportivos el desempeño de la selección de fútbol. El estadio donde se jugó la inauguración y la final, el Monumental de River Plate, estaba a 200 metros de distancia del peor campo de concentración y extermino de la dictadura, la tenebrosa Escuela de Mecánica de la Armada (ESMA). Los costos fueron elevadísimos: el costo fue superior al del torneo siguiente, en España, a pesar de que hubo ocho equipos menos disputando partidos. Los grupos de exiliados políticos en Europa movilizaron en favor de un boicot de los equipos europeos alegando las desapariciones y torturas que practicaba el gobierno militar, pero ningún gobierno o asociación deportiva lo acató. Mucho menos lo hizo la FIFA, que desde 1974 estaba gobernada por el único latinoamericano que llegó a presidirla, el brasileño João Havelange, quien apoyó explícitamente 
a la dictadura argentina; después de todo, era un reconocido partidario de la contemporánea dictadura brasileńa. No conforme con el apoyo, Havelange nombró como vicepresidente de la FIFA, en los años siguientes, al argentino Carlos Lacoste, alto oficial de la Marina, principal responsable de la organización de la Copa y reiteradamente acusado por la corrupción desenfrenada que la rodeó.

De todas maneras, también se jugó al fútbol, con la presencia del todavía buen equipo peruano que ganó su grupo, un Brasil que no acababa de procesar la herencia post Pelé y pasó con lo justo a la segunda rueda, y un México que fracasó con dureza: tres jugados, tres perdidos, doce goles en contra y solo dos a favor. Pero los tres equipos sudamericanos quedaron en el mismo grupo en la segunda ronda, junto a Polonia. Perú perdió con Brasil y Polonia con Argentina en la primera fecha; Perú volvió a ser derrotado por Polonia en la segunda, mientras Brasil y Argentina igualaban en cero. En la tercera fecha, Brasil venció a Polonia por 3 a 1 dos horas antes del partido entre Argentina y Perú, obligando al equipo local a vencer por cuatro goles para poder pasar a una final con Holanda.

Como todo el mundo sabe, Argentina venció 6 a 0.

La discusión sobre el partido con Perú comenzó mucho después del torneo: nadie puso en duda, en la Argentina, la legitimidad y legalidad del triunfo, a pesar de que en el resto del mundo - en primer lugar, en la prensa brasileña - el partido fue rápida y reiteradamente calificado como producto de un acto de corrupción, de negociaciones gobierno a gobierno, de sobornos masivos. En 1979, el jugador peruano Rodulfo Manzo, a la sazón jugando en Vélez Sarsfield de Argentina, afirmó en una conversación con sus nuevos compańeros que todos los jugadores peruanos cobraron sobornos, con la excepción de Juan José Muñante. Por su parte, el periodista argentino Pablo Llonto obtuvo el testimonio del jugador Juan Carlos Oblitas, que en 1986 sostuvo: "Cuatro o cinco jugadores peruanos recibieron dinero».

A su vez, Ricardo Gotta, el periodista argentino que trabajó con más detalle el partido fatídico, enumera la confesión de Manzo, ciertas llamadas sospechosas entre funcionarios argentinos y peruanos, la donación de trigo — que estima en dos millones de dólares-, la fluidez del contacto entre ambas dictaduras y que el propio hijo del dictador peruano Morales Bermúdez presidía la delegación. Pero, además, despliega un análisis del partido en el que resalta una larga serie de errores de los defensores peruanos - especialmente, el propio Manzo-, errores inexplicables en ese nivel (Gotta, 2008).

La mejor interpretación la ofreció el documental Mundial 78: la historia paralela, con guion del periodista deportivo argentino Ezequiel Fernández Moores, en 2003. El filme fue el primero en afirmar el hecho de que el dictador Videla visitó el vestuario peruano, acompañado nada menos que por el ex secretario de Estado norteamericano Henry Kissinger, para hablar de la unidad latinoamericana y desear 
suerte a los deportistas. Juan Carlos Oblitas, en el documental, no duda en señalar el hecho como una presión, aunque desconoce la existencia de sobornos u otras sugerencias explícitas, a pesar de que había dicho otra cosa en 1986. Como presión para los jugadores peruanos parece suficiente: no se sabe que Videla haya violado la intimidad del vestuario argentino en ninguna oportunidad antes de los partidos -aunque siempre visitó a los jugadores después—, y su presencia esa noche parece haber funcionado como una exitosa y sugestiva maniobra. Con sobornos o sin embarques de trigo: con la presencia de Videla debe haber sido suficiente.

\section{¿OPIO DE LOS PUEBLOS?}

Sin embargo, en medio del dolor y la represión de las dictaduras, el fútbol funcionó a veces como un espacio de liberación. Por supuesto, esto supone contrariar la tesis del opio moderno de los pueblos, que cundió entre los sectores intelectuales desde finales de la década de 1960 en el continente, según la cual el fútbol aparecía como sucedáneo de la religión a la hora de embrutecer y alienar las conciencias populares. Gracias al fútbol, se afirmaba, los públicos distraían su atención de lo realmente importante - la explotación, el totalitarismo - para ocuparse de banalidades tan enormes como los goles de Pelé o Maradona. Y en América Latina se trataba, sistemáticamente, de dictaduras militares conservadoras de derecha: nunca de regímenes «populistas».

Esta tesis fue ampliamente rebatida a comienzos de la década de 1980 por los primeros estudiosos del fútbol en el continente, especialmente el antropólogo brasileño Roberto Da Matta. En 1982, en una compilación titulada O universo do futebol, Da Matta rechazaba esa interpretación mostrando cómo el mundo del fútbol permitía una representación de los dilemas y conflictos de la sociedad brasileña — su injusticia, su racismo—y no su ocultamiento (Da Matta, 1982). Pero, al mismo tiempo, el fútbol permitía una ficción, que todos los hinchas entendían como tal, pero a la vez disfrutaban: la de la igualación transitoria, la de una democracia imaginada en el espacio del juego, la del espacio donde el débil puede vencer al poderoso. De ese modo, la dictadura brasileña podía festejar el triunfo de México 1970 como propio, mientras los públicos se entregaban (¿con astucia?) a la celebración carnavalesca —es decir, esa celebración que invierte las jerarquías y libera los cuerpos y las almas, aunque más no sea transitoriamente. Lo mismo podía decirse de las celebraciones populares en la Argentina de 1978: fueron las únicas veces en que se pudieron ocupar las calles, en medio del terror dictatorial, celebrando un triunfo deportivo que no incluía, necesariamente, a los opresores: las movilizaciones porteńas evitaron pisar la Plaza de Mayo, el centro político del país, a donde concurrían habitualmente las manifestaciones políticas populares. Los hinchas celebraban 
a sus jugadores, no necesariamente a sus dictadores. Ambas dictaduras, indiscutiblemente, buscaron capitalizar políticamente los éxitos; nunca pudo probarse, indiscutiblemente, que lo hayan conseguido.

\section{BRASIL 2014, O EL REGRESO DE LA MÁQUINA ESTATAL-POPULISTA}

Distinta fue la situación a partir de las transiciones democráticas de finales de la década de 1980 en América Latina. El mismo exceso dictatorial de las décadas pasadas obligó a cierto recato de los gobiernos democráticos en su uso del deporte: la asociación franca de las dictaduras con las competencias futbolísticas y su utilización política - aunque, como dijimos, nunca se comprobara su eficacia real en términos de comportamientos sociales - llevó a los nuevos gobiernos democráticos a cuidar esa relación. La década de 1990, conocida como «los años neoliberales» en todo el continente, implicaron gobiernos conservadores que, sin embargo, utilizaban retóricas neopopulistas de derecha. De todas maneras, la relación entre política y fútbol continuó organizada por el mito que ya explicamos: la confianza absoluta de las elites políticas en la capacidad del fútbol para «distraer a las masas», sin ninguna prueba que confirmara su eficacia. Como analizó Alabarces en Fútbol y Patria, en 2012, las retóricas neopopulistas - la celebración de una presunta «unidad nacional» de consumidores futbolísticos_ - quedaron cargo del mercado: el periodismo, la publicidad, el marketing.

La llegada del nuevo siglo significó la aparición en casi toda América Latina de gobiernos progresistas, caracterizados como una «marea rosada» en la literatura política norteamericana (como lo hacen Marc Zimmerman y Luis Ochoa Bilbao). Los grupos conservadores decidieron que el término que mejor los definía era "populistas»: sin embargo, el único rasgo común eran algunas políticas de distribución más equitativa de la renta. Las retóricas futbolísticas no se modificaron: siguieron siendo retóricas del mercado antes que gubernamentales. Incluso, es llamativo que el presidente latinoamericano que más importancia le dio a los símbolos futbolísticos fuera el conservador colombiano Juan Manuel Santos (2010-2018), que incluso desarrollaba las campañas políticas vestido con la camiseta nacional. Y no se trataba de un "populista»: por el contrario, se enfrentó duramente con el presidente venezolano Hugo Chávez (1999-2013), una suerte de símbolo de los "populismos» progresistas del continente. Un buen caso para analizar es, en ese sentido, la experiencia de los gobiernos kirchneristas (por Néstor Kirchner y su esposa, Cristina Fernández de Kirchner, presidentes democráticos entre 2003-2007 y 2007-2015, respectivamente).

El kirchnerismo había propuesto una nueva validez para los discursos tradicionales del peronismo: el viejo relato nacional-popular, con cierta adecuación a 
los nuevos tiempos que incluía la condena de la década neoliberal —aunque también hubiera sido liderada por el peronista Carlos Menem (1989-1999). Esa nueva validez implicaba la afirmación explícita del retorno del Estado como actor central de la vida social y económica. Aunque esto no se verificara por completo - la organización económica siguió estando centralmente en manos de las corporaciones privadas-, la afirmación fue estentórea: el Estado había regresado para cumplir las funciones que nunca debió haber perdido. Entre ellas, sus funciones narrativas.

El rol central del Estado como narrador patriótico en la sociedad argentina había retornado con fuerza. Ante eso, el fútbol no podía proponer discursos alternativos, porque jamás lo había hecho, ni siquiera en tiempos conservadores. Cuando la figura de Maradona había permitido algún relato al menos autónomo, este había consistido en exhibir la continuidad del viejo relato nacional-popular del peronismo. Al retornar este a escena, y nuevamente propuesto por el Estado, como en los viejos y añorados tiempos del primer peronismo — que continúa funcionando como una suerte de Edad Dorada de la Argentina moderna-, el fútbol no podía volver a encarnar ningún relato nacional eficaz. Apenas proponer su supervivencia como mercancía, a cargo, una vez más, del mercado, con la publicidad comercial como gran soporte de sus textos. En tanto los sentidos de la patria habían vuelto a discutirse en los espacios políticos, al fútbol solo le quedaban las retóricas vacuas pero altisonantes de los sponsors, que continuaron plagadas de los lugares comunes de las prédicas patrioteras.

El problema es que también lo hizo el Estado argentino.

En 2009 había aparecido el programa Fútbol para Todos, la estatización de las transmisiones futbolísticas argentinas, complementado en 2011 por Deporte para Todos, que establecía la obligatoriedad de transmitir por televisión abierta cualquier evento deportivo que involucrara en instancias decisivas a deportistas argentinos. Se presentó así una política de patrimonialización de lo deportivo — es decir, considerar patrimonio público ciertos bienes intangibles, en tanto que productos culturales y mediáticos. El Estado argentino había producido, entonces, un instrumento jurídico que afirmaba finalmente la relación entre deporte y patria, en tanto patrimonio de la cultura nacional-popular: una suerte de afirmación definitiva de las posibilidades nacionalistas del deporte. Pero se limitó a producirlo — solo podía producirlo - como mercancía cultural: una suerte de ratificación de que, a pesar de las tentaciones democráticas, la lógica dominante es la de la industria cultural. Y allí no hay patria que no sea simplemente mercancía. Los deportes que el Estado nacional incorporaba como patrimonio eran, claro, solo los deportes con audiencias televisivas importantes: el resto no le preocupaba.

Pero en 2014 las cosas se complicaron. Porque Fútbol para Todos — nuevamente: el Estado nacional_ adquirió los derechos exclusivos de la transmisión del Mundial 
de Brasil, con lo que monopolizó casi toda la voz televisiva, al menos la de acceso abierto (la cadena de cable TyC Sports también transmitió los partidos de Argentina, así como la cadena satelital Direct TV). Primero presentó a sus periodistas formados como un equipo de fútbol, con trajes, pero también camisetas argentinas y botines, coreando el Himno Nacional en un campo de juego y remedando los movimientos de los jugadores, con el eslogan «un equipo de fútbol y un equipo de periodistas para una única pasión argentina»: la cobertura periodística se asimilaba, entonces, a la propia práctica futbolística como representativa. Digámoslo así: los periodistas también salían a la conquista de la Copa, lo que podría explicar por qué los relatos fueron tan insoportablemente patrioteros, tan gritones, tan xenófobos, y hasta racistas.

Junto a los desempeños periodísticos circulaban las publicidades estatales. Como en el fútbol local, la trasmisión estatal priorizó los spots de difusión de sus propagandas. Alguna, políticamente correcta, condenaba la trata de personas en los grandes eventos. Otras banalizaban las políticas presuntamente exitosas de «inclusión» social —obtener un crédito para una casa, graduarse en una universidad nueva - transformándolas en festejos de goles de sus beneficiarios (una vuelta de tuerca ahora explícita a la futbolización de lo social y lo político). Pero el clímax llegaba en el spot «Nadie gana un Mundial solo», que asimilaba todos los «logros» de los gobiernos kirchneristas a los avatares de la selección de fútbol: «para ganar hay que tener un país unido». El periodista Horacio Verbitsky, militante del kirchnerismo, afirmaba que se trataba de «una falacia que desciende en línea directa de la retórica que la dictadura utilizó durante el campeonato de 1978 y que se reiteró en los relatos insoportables del relator de los partidos argentinos. [...] Esta pieza constituye una banalización insoportable y un uso espurio de cosas demasiado serias» (Verbitsky, 2014).

\section{CONCLUSIÓN TEÓRICA, COMO SIEMPRE PROVISORIA}

Por cierto: la semejanza que Verbitsky encontraba con el discurso de la dictadura es solo eso, semejanza. No se trata de identidad. La continuidad está en el deseo, común a gobiernos democráticos y autoritarios, conservadores o populistas, de utilizar presuntos beneficios del fútbol en su provecho: como manipulación o como transferencia del éxito deportivo al éxito político. Como señalamos, la dictadura buscaba al mismo tiempo la famosa "cortina de humo» y el consenso civil; en el caso del kirchnerismo, la intentona fue la de asociar un buen desempeño deportivo a un relato de época, el nacional-popular.

En la Copa del Mundo de 2018, tanto los nuevos gobiernos conservadores

—que sucedieron a gobiernos presuntamente «populistas» y progresistas - de 
Argentina y Brasil, como los que ya eran conservadores, como los de Colombia, México, Panamá, Perú o Costa Rica, desplegaron las mismas retóricas nacionalistas que asociaban los sucesos deportivos con la presunta o discutida grandeza nacional. No hubo entre ellos diferencias, sino de grado - la perseverante utilización de la camiseta nacional por el presidente colombiano Santos; el vocabulario sistemáticamente futbolero del presidente argentino Macri; la ceremonia de «embanderamiento» —asignación de una bandera oficial — del equipo mexicano por el presidente Peña Nieto. Todos ellos, presidentes conservadores y opositores acérrimos a un presunto populismo.

Sencillamente, se trata de la combinación de dos lógicas, que la bibliografía tendió a describir como enfrentadas e irreductibles: por un lado, la nacional-popular, que entiende al Estado como una máquina productora de significaciones democráticas, y por otro la neoliberal-conservadora, que confía en el mercado - al que llama sociedad civil — como único enunciador y narrador. En realidad, vemos aquí los puntos de contacto entre populismo y neoliberalismo: el populismo se limita a agregar pasión, afectividad y masividad a lo que el neoliberalismo ya ha vuelto mercancía televisiva. En definitiva, aún con la novedad de la patrimonialización del deporte televisado argentino — radicalmente original en el contexto latinoamericano, donde ningún Estado se ha atrevido a interferir en los gigantescos negocios de las cadenas-, estos procesos podrían describirse como un nuevo pliegue: la conciliación de ambas lógicas políticas y narrativas.

O podríamos proponer otra definición: en última instancia, todos son populistas.

\section{REFERENCIAS}

Alabarces, P. (2002). Fútbol y patria. El fútbol y las narrativas de la Nación en Argentina. Buenos Aires: Prometeo.

Alabarces, P. (2014). Héroes, machos y patriotas. El fútbol, entre la violencia y los medios. Buenos Aires: Aguilar.

Alabarces, P. (2018). Historia minima del fútbol en América Latina. México, D. F.: El Colegio de México.

Bayer, O. (1990). Fútbol argentino. Buenos Aires: Sudamericana.

Elsey, B. (2011). Citizens and sportsmen: fútbol and politics in twentieth-century Chile. Austin: University of Texas Press.

Gotta, R. (2008). Fuimos campeones. La dictadura, el Mundial 78 y el misterio del 6 a 0 a Perú. Buenos Aires: Edhasa.

Llonto, P. (2005). La vergüenza de todos. Buenos Aires: Editorial de las Madres de Plaza de Mayo.

Matta, R. (ed.) (1982). O universo do futebol: esporte e sociedade brasileira. Río de Janeiro: Pinakotheke. 
Ortiz, R. (1991). Lo actual y la modernidad. Nueva Sociedad, 116, 94-101.

Panfichi, A. (ed.) (2008). Ese gol existe. Una mirada al Perú a través del fútbol. Lima: Pontificia Universidad Católica del Perú.

Rein, R. (2015). La cancha peronista: fútbol y politica 1946-1955. San Martín: UNSAM.

Rinke, S. (2007). ¿La última pasión verdadera? Historia del fútbol en América Latina en el contexto global'. Iberoamericana, VII, 27, 85-100

Verbitsky, H. (2014). Vamos, Argentina. Página 12, 6/7/14, 10. 